\title{
Marine fungal metabolite 1386A alters the microRNA profile in MCF-7 breast cancer cells
}

\author{
BING TANG $^{1 *}$, WEI-LING HE ${ }^{1 *}$, CHENG ZHENG $^{2}$, TUCK-YUN CHEANG ${ }^{1}$, \\ XI-FANG ZHANG ${ }^{3}$, HUI WU ${ }^{1}$ and HUI-LING YANG $^{4}$ \\ ${ }^{1}$ Department of Gastrointestinal and Pancreatic Surgery, The First Affiliated Hospital of Sun Yat-sen University, \\ Guangzhou 510080; ${ }^{2}$ Department of Ophthalmology, Zhaoqing No. 1 People's Hospital, \\ Zhaoqing 526021; ${ }^{3}$ Zhongshan Ophthalmic Center, and ${ }^{4}$ Department of Pathophysiology, \\ Sun Yat-sen University, Guangzhou 510080, P.R. China
}

Received July 28, 2011; Accepted December 6, 2011

DOI: $10.3892 / \mathrm{mmr} .2011 .697$

\begin{abstract}
Marine fungal metabolite 1386A is a newly identified small molecular compound extracted from the mangrove fungus 1386A in the South China Sea. Preliminary experiments have demonstrated its amazing cytotoxity to cancer cells, while the mechanism remains poorly understood. microRNAs (miRNAs) are a newly identified class of small regulatory RNAs which play an important role in gene regulation at the post-transcriptional level. They usually function as oncogenes or tumor suppressors and are related to drug sensitivity and resistance. We aimed to test the hypothesis that the potential antineoplastic compound, 1386A, alters the miRNA profile in MCF-7 and whether its unknown mechanism may be predicted by analysis of the altered miRNA profile. Cell proliferation was analyzed by MTT assay. The alteration of the miRNA expression profile of MCF-7 cells was investigated using advanced microarray technology. Silico analysis using TargetScan was used to predict the putative targeted transcripts encoding the dysregulated miRNAs. 1386A inhibited MCF-7 cell proliferation in a time- and dose-dependent manner (the $\mathrm{IC}_{50}$ value at $48 \mathrm{~h}$ was $17.1 \mu \mathrm{mol} / \mathrm{l}) .1386 \mathrm{~A}(17.1 \mu \mathrm{mol} / \mathrm{l})$ significantly altered the global miRNA expression profile of the MCF-7 cells at $48 \mathrm{~h}$. Forty-five miRNAs were differentially expressed in MCF-7 cells. Target prediction suggested that these miRNAs potentially target many oncogenes and tumor-suppressor genes associated with cancer development, progression and metastasis. The promising antineoplastic compound marine fungal metabolite 1386A alters the miRNA profiles of MCF-7
\end{abstract}

Correspondence to: Dr Hui-Ling Yang, Department of Pathophysiology, Sun Yat-sen University, Guangzhou 510080, P.R. China E-mail: hlyangsums@hotmail.com

*Contributed equally

Key words: anticancer drug pharmacology, antineoplastic agents, breast cancer, gene expression regulation, TGF- $\beta$ breast cancer cells. Analyzing the alteration of the miRNA profile caused by this potential antineoplastic compound may help to predict the unknown mechanism of 1386A.

\section{Introduction}

The mangrove is a characteristic plant of tropical and subtropical zones, which lives in soils in sea coasts and river mouth regions. The physiological and ecological uniqueness of the mangrove forest makes it an outstanding habitat for marine microorganism. Natural products of these marine microorganisms are becoming a new source of potential antineoplastic drugs (1-4). 1386A is a newly discovered natural compound, extracted from mangrove fungus which has a symbiotic relationship with the mangrove forest. Preliminary studies have shown that 1386A owns potential antineoplastic properties, which were tested in detail in the present study. microRNA (miRNA) microarray expression analysis was employed to investigate the unknown mechanism of 1386A, predicting the putative effect targets and signaling pathway.

miRNAs have recently been the central interest of human molecular oncology, owning to their unique stimulatory and inhibitory actions in breast cancer. They are a group of small (20-22 nt) endogenous non-protein-coding RNA molecules that negatively regulate gene expression $(5,6)$, through binding to the 3'-untranslated region (3'-UTR) of target mRNAs leading to mRNA cleavage or translation inhibition $(7,8)$. It has been predicted that miRNAs target more than $30 \%$ of proteincoding genes (9). This was confirmed by studies proving the significance of miRNAs in various biological processes, including stem cell maintenance and differentiation, disease, cell proliferation and apoptosis (10-14). Most miRNA targets are localized in cancer-associated genomic regions or in fragile sites (15), where oncogenes and tumor-suppressor genes, which play critical roles in tumorigenesis $(16,17)$ and metastasis (18), are located. Aberrant miRNA expression levels have been reported in almost all human cancers (17,19-22). Some of them display a unique expression profile in specific types of cancers (21), suggesting their potential use as novel biomarkers for cancer diagnosis (23) and as alternative cancer treatment 
targets. In respect to breast cancer, miR-21 was found to be up-regulated, whereas miR-125b and miR-145 were downregulated in MCF-7 cells (20). Regarding MDA-MB-231 cells, miR-21, miR-9 and miR-10b were up-regulated, while miR-145 was down-regulated $(20,24)$. Thus, miRNAs were confirmed to modulate breast cancer initiation, invasion and metastasis (24-26).

At present, several studies have suggested the importance of miRNAs in modulating the chemosensitivity and chemoresistance of tumor cells (27-29). Si et al reported that suppression of miR-21 sensitized MCF-7 cells to topotecan (30) and enhanced chemosensitivity of leukemic HL60 cells to arabinosylcytosine (31). Similar studies exist for the drugs gemcitabine, doxorubicin and tamoxifen (32-34). Furthermore, miR-15b and miR-16, have been proved to modulate multi-drug resistance (35). The importance of miRNAs in drug sensitivity and resistance is illustrated in the above studies, and the intrinsic role of miRNAs in managing the efficiency of chemotherapy in certain human cancers has been revealed (37).

Regarding the critical function of miRNAs as oncogenes or tumor suppressors and their correlation to drug sensitivity and resistance, it is reasonable to hypothesize that the properties of antineoplastic drugs may be related to its alteration of miRNA profiles. Furthermore, extensive research offers the hope of targeting miRNAs as alternative cancer treatments. For instance, it has been demonstrated that the modulation of specific miRNA alterations in cancer cells using miRNA replacement or anti-miRNA technologies restore miRNA activities, repair the gene regulatory network, signalize pathways and reverse the phenotype of cancerous cells. 5-FU was reported to be able to modify the expression of several miRNAs in colon cancer cells (36), and its cytotoxicity to breast cancer may be partially elicited by regulation of miRNA expression levels (37). Consequently, the direct or indirect interference of miRNAs with certain small molecules may be of great pharmaceutical value in the future, and miRNA profile analysis alone may be applied to predict the unknown mechanism of activation of newly identified compounds. However, relevant studies are seldom reported.

Recently, a natural small molecular compound, 1386A, was newly identified. It is hypothesized that 1386A modifies the expression profiles of miRNAs in MCF-7 cells and that, by analyzing the alteration of the miRNA expression pattern, the mechanism of activation of 1386A may be roughly predicted. In the present study, the global analysis of miRNAs was introduced to predict the mechanism of the putative function of 1386A for the first time. MTT assay was applied to investigate the detailed cytotoxicity of $1386 \mathrm{~A}$ to MCF-7. Microarray technology was employed to investigate the effect of $1386 \mathrm{~A}$ exposure on the global expression profile of miRNAs in MCF-7 cells, and alteration of the global miRNA profiles was analyzed to predict the mechanism of the putative effect of 1386A.

\section{Materials and methods}

Reagents. 1386A, presented by the School of Chemistry and Chemical Engineering, Sun Yat-sen University, as a gift, was stored at $4^{\circ} \mathrm{C}$ in PBS for less than 2 weeks and kept away from light and moisture. DMEM medium was from Gibco
(Rockville, MD, USA). Fetal bovine serum (FBS) was from Sijiqing Biological Engineering Materials (Zhejiang, China). Other reagents were from Sigma (St. Louis, MO, USA).

Cell line and cell culture. The MCF-7 human breast adenocarcinoma cell line, purchased from the Cell Repository of Sun Yat-sen University, was maintained at $37^{\circ} \mathrm{C}$ in a humidified incubator with $5 \% \mathrm{CO}_{2}$, cultured in high-glucose DMEM medium (Gibco) containing L-glutamine and $25 \mathrm{mM}$ HEPES, and supplemented with $10 \% \mathrm{FBS}$, penicillin (100 U/ml) and streptomycin $(100 \mu \mathrm{g} / \mathrm{ml})$. Cells in the mid-log phase were used for the experiments.

Cell viability assay. MCF-7 cells were seeded onto 96-well microplates $\left(1 \times 10^{4}\right.$ cells/well) and cultured for $12 \mathrm{~h}$. Then, the cells were treated with complete media or $1386 \mathrm{~A}$ at final concentrations of $5,10,15,20$ and $25 \mu \mathrm{mol} / 1$, respectively. Cell viability was assessed using an MTT assay at 24, 48, 72 and $96 \mathrm{~h}$ after $1386 \mathrm{~A}$ treatment. The absorbance value (A) at $570 \mathrm{~nm}$ was read using an automatic multi-well spectrophotometer (Sunrise, Beijing, China). The fifty percent inhibition concentration $\left(\mathrm{IC}_{50}\right)$ and their $95 \%$ confidence limits were calculated and compared by weighted probit analysis (Bliss and Finney). All data were analyzed using SPSS16.0. The p-values of the t-test were also calculated. P-values $<0.01$ were considered to denote significant differences. Each tested concentration and the controls were repeated 24 times.

miRNA isolation. Cells were seeded in 6 flat-bottom culture tubes in $10 \mathrm{ml}$ of complete medium. After $12 \mathrm{~h}$, the media were replaced by complete media (control group) or 1386A at a final concentration of $17.1 \mu \mathrm{mol} / 1$ (treatment group), and cells were re-incubated for $48 \mathrm{~h}$. Total RNA was extracted by the TRIzol method (Invitrogen, USA) according to the manufacturer's instructions. RNA quantity and quality were analyzed using a NanoDrop Spectrophotometer (NanoDrop Technologies, Wilmington, DE, USA) and immediately stored at $-80^{\circ} \mathrm{C}$.

miRNA mircoarray expression analysis. The assay was performed on $\sim 5 \mu \mathrm{g}$ of total RNA sample. The total RNA was size-fractionated using a YM-100 Microcon centrifugal filter (Millipore, Billerica, MA, USA) and RNA sequences of $<30 \mathrm{nt}$ were isolated. These small RNAs were then extended at the 3 '-end with a poly(A) tail using poly(A) polymerase, followed by ligation of an oligonucleotide tag to the poly(A) tail for fluorescence staining. Two different tags (Cy3 and Cy5) were used for the two different RNA samples (control and 1386A-treated RNA samples). The two RNA samples were then hybridized overnight on a $\mu$ Paraflo $^{\mathrm{TM}}$ microfluidic chip using a microcirculation pump (Atactic Technologies Inc., Houston, TX, USA) (38). Each microfluidic chip contained detection probes, positive control probes and negative control probes. The detection probes were made in situ by photogenerated reagent (PGR) chemistry. These probes consisted of chemically modified nucleotide coding sequences complementary to the target miRNAs (all 837 human miRNAs listed in the Sanger's miRNA miRBase, release $11.0 \mathrm{http} / /$ microrna. sanger.ac.uk/sequences/) and a spacer segment of polyethylene glycol to extend the coding sequence away from the substrate. A total number of 50 positive and negative control probes 
were included to ensure uniformity of the assay conditions and sample labeling. Chemical modifications of the probes were carried out to balance the melting temperatures of hybridization. RNA Hybridization was performed using $100 \mu \mathrm{l}$ of $6 \mathrm{X}$ SSPE buffer $\left(0.9 \mathrm{M} \mathrm{NaCl}, 6 \mathrm{mM}\right.$ EDTA, $60 \mathrm{mM} \mathrm{Na}_{2} \mathrm{HPO}_{4}$, pH 6.8) containing $25 \%$ formamide at $34^{\circ} \mathrm{C}$. After hybridization, control and 1386A-treated cells were dye-stained using tag-conjugating dyes $\mathrm{Cy} 3$ and $\mathrm{Cy} 5$, respectively. A laser scanner (GenePix 4000B, Molecular Devices) was used to collect the fluorescent images, which were then digitized using Array-Pro image analysis software (Media Cybernetics).

Statistical analysis of miRNA microarray data. The microarray data were analyzed by subtracting the background, and the signals were normalized using a locally weighted regression (LOWESS) filter as another report (39). Detectable miRNAs were selected based on the following criteria: signal intensity higher than 3 times (background standard deviation); spot CV $<0.5$ (where CV = standard deviation/signal intensity); and signals from at least two out of the four replicates are above the detection level. To identify miRNAs whose expression differed between control and 1386A-treated MCF-7 cells, statistical analysis was performed. The ratio of the two sets of detected signals (control and treated) was calculated and expressed in $\log 2$ scale (balanced) for each miRNA. The miRNAs were then sorted according to their differential ratios. The $p$-values of the t-test were also calculated. miRNAs with p-values $<0.01$ and $\log 2$ ratio $>0.5$ were considered to be significantly differentially expressed. Each miRNA was analyzed four times, and the controls were repeated four to sixteen times.

\section{Results}

Effect of $1386 \mathrm{~A}$ on the MCF-7 human breast cancer cell line. 1386A significantly reduced the viability of MCF-7 cells beginning at $48 \mathrm{~h}$ in both time- and concentration-dependent manners (Figs. 1 and 2). At $96 \mathrm{~h}$, the inhibitory effect reached a maximum, with inhibition rates of 60,73 and $85 \%$ at concentrations of 15,20 and $25 \mu \mathrm{mol} / 1$, respectively. The $\mathrm{IC}_{50}$ value and their $95 \%$ confidence limits of $1386 \mathrm{~A}$ at $24,48,72$ and $96 \mathrm{~h}$ were 24.0 (21.8-26.2), 17.1 (15.6-18.4), 16.9 (14.4$17.5)$ and 14.9 (14.4-15.3) $\mu \mathrm{mol} / \mathrm{l}$, respectively. The growth of MCF-7 cells was completely inhibited without significant alteration, when MCF-7 cells were treated for $48 \mathrm{~h}$ with 15 or $20 \mu \mathrm{mol} / 1$ 1386A (Fig. 1). This result indicates the promising cytotoxity of 1386A to MCF-7 cells, as well as its potential antineoplastic properties. This treatment time $(48 \mathrm{~h})$ and dose $\left(\mathrm{IC}_{50}=17.1 \mu \mathrm{mol} / \mathrm{l}\right)$ were proposed to be appropriate for the study of the relationship between the effect of 1386A on the global expression levels of miRNAs in MCF-7 cells and its potential antineoplastic mechanism.

Alteration of the miRNA expression profile in MCF-7 cells after $1386 \mathrm{~A}$ treatment. 1386A treatment significantly altered the miRNA expression profile in MCF-7 cells. miRNA microarray analysis identified 45 miRNAs which showed significant dysregulation between the 1386A-treated and control samples (Table I). The control cells expressed 211 miRNAs, while the treated cells expressed 394 miRNAs, which shows that $1386 \mathrm{~A}$ exposure resulted in a higher number of expressed

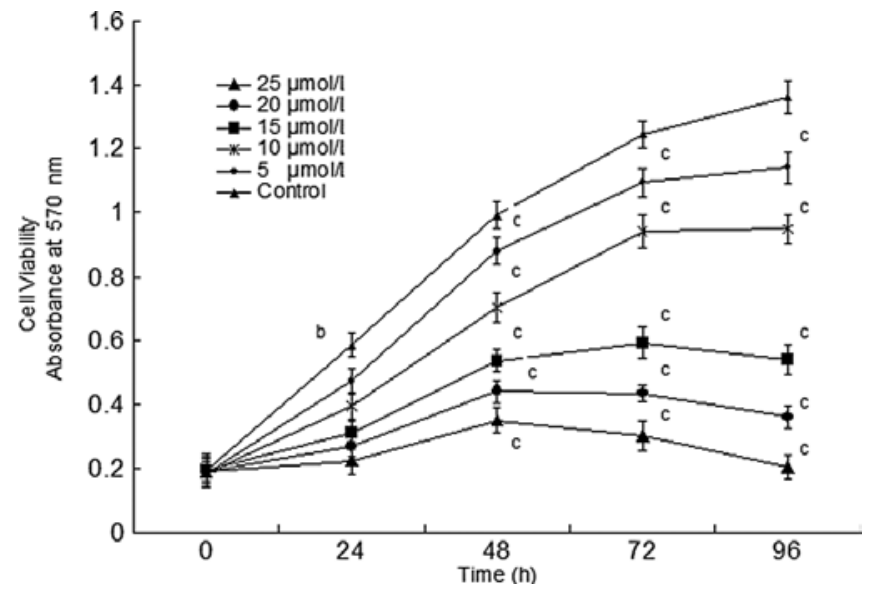

Figure 1. Growth curve of MCF-7 cells after treatment with different concentrations of 1386A. The inhibitory effect of 1386A on MCF-7 was increased along with increasing concentrations at all time points. 1386A inhibited the growth of MCF-7 cells in a dose-dependent manner. When treated with $1386 \mathrm{~A}$ at $15 \mu \mathrm{mol} / 1$ for $48 \mathrm{~h}$, a significant inhibitory effect was achieved. ${ }^{\mathrm{b}} \mathrm{P}<0.01$, all tested groups vs. the control group; ${ }^{\mathrm{C}} \mathrm{P}<0.01$, single tested group vs. the control group.

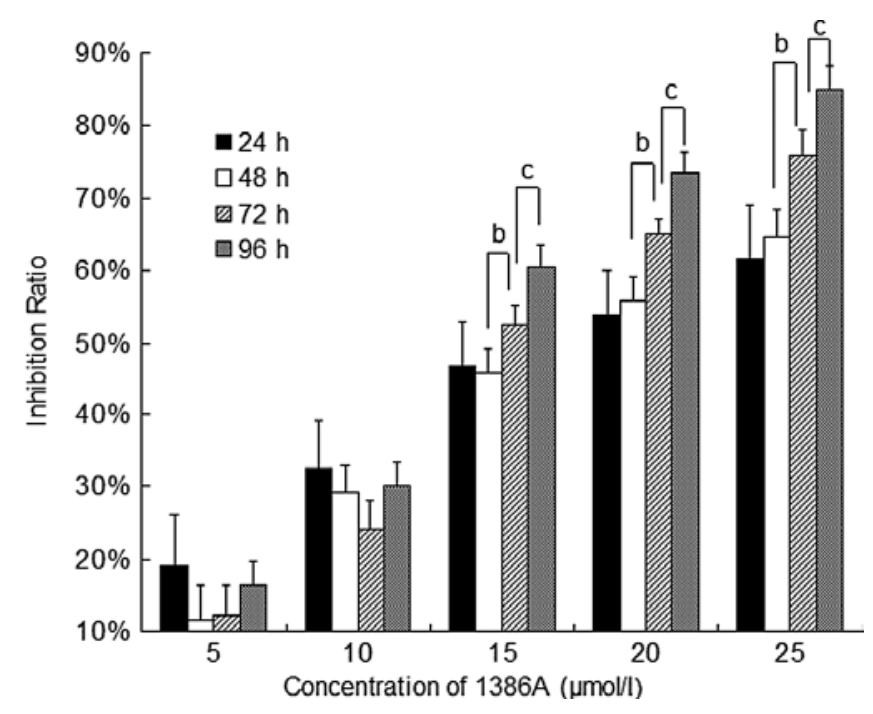

Figure 2. Inhibition ratio of $1386 \mathrm{~A}$ at different treatment times. Timedependent inhibition of 1386A in MCF-7 cells at different time points. ${ }^{\mathrm{b}} \mathrm{P}<0.01,48$-h group vs. the 72 -h group; ${ }^{\mathrm{P}} \mathrm{P}<0.01,72$-h group vs. the $96-\mathrm{h}$ group.

miRNAs and significant alteration of the expression levels of those miRNAs, as compared to the control cells. Statistical analysis of the differentially expressed miRNAs showed that 45 miRNAs were significantly dysregulated with $>1$-fold change $(\mathrm{P}<0.01)$, while the remaining miRNAs were not significantly differentially expressed (Fig. 3). The changes in miRNA levels were generally limited, with several exceptions, such as 12.30- and 8.88-fold up-regulation of miR-663 and miR-654-5p, respectively. This suggests that the effects of 1386A on miRNA populations were not global, but rather miRNA-specific. Among the 45 miRNAs, 21 (47\%) were up-regulated, while 23 (53\%) were down-regulated (Table I, Fig. 3). Fold-change comparisons of the significantly altered miRNAs are shown in Fig. 3. miRNAs showing at least a 
Table I. Comparison of miRNA expression profile between the control and 1386A-treated groups.

\begin{tabular}{|c|c|c|c|c|c|}
\hline No. & Probe_ID & Sample A signal & Sample B signal & Fold change & $\begin{array}{c}\log 2(\text { Sample B/ } \\
\text { Sample A) }\end{array}$ \\
\hline 1 & hsa-miR-663 & 76.62 & 972.73 & 12.70 & 3.62 \\
\hline 2 & hsa-miR-654-5p & 11.92 & 101.91 & 8.55 & 3.15 \\
\hline 3 & hsa-miR-150 & 113.92 & 19.49 & -5.85 & -2.51 \\
\hline 4 & hsa-miR-638 & 565.28 & $1,096.56$ & 1.94 & 0.95 \\
\hline 5 & hsa-miR-125b & 972.33 & 567.44 & -1.71 & -0.80 \\
\hline 6 & hsa-miR-7 & $2,524.08$ & $4,203.02$ & 1.67 & 0.75 \\
\hline 7 & hsa-miR-181b & $1,153.23$ & $1,917.19$ & 1.66 & 0.72 \\
\hline 8 & hsa-miR-1308 & $4,223.49$ & $2,694.55$ & -1.57 & -0.69 \\
\hline 9 & hsa-miR-93 & $2,749.05$ & $1,742.77$ & -1.58 & -0.65 \\
\hline 10 & hsa-miR-320c & $3,210.61$ & $2,047.36$ & -1.57 & -0.61 \\
\hline 11 & hsa-miR-1246 & $3,884.86$ & $6,004.81$ & -0.65 & 0.61 \\
\hline 12 & hsa-miR-320d & $2,237.00$ & $1,437.28$ & -1.56 & -0.61 \\
\hline 13 & hsa-miR-320a & $3,255.32$ & $2,125.71$ & -1.53 & -0.59 \\
\hline 14 & hsa-miR-182 & $3,981.53$ & $2,737.23$ & -1.45 & -0.58 \\
\hline 15 & hsa-miR-720 & $1,908.47$ & $1,284.32$ & -1.49 & -0.54 \\
\hline 16 & hsa-miR-320b & $2,396.55$ & $1,618.55$ & -1.48 & -0.53 \\
\hline 17 & hsa-miR-21 & $33,950.19$ & $50,183.62$ & 1.48 & 0.53 \\
\hline 18 & hsa-miR-181a & $1,358.49$ & $1,930.09$ & 1.42 & 0.51 \\
\hline 19 & hsa-miR-375 & $1,868.18$ & $1,328.26$ & -1.41 & -0.49 \\
\hline 20 & hsa-miR-374a & 923.77 & $1,256.41$ & 1.36 & 0.49 \\
\hline 21 & hsa-miR-27b & 778.22 & $1,078.14$ & 1.39 & 0.47 \\
\hline 22 & hsa-miR-1826 & $17,532.46$ & $24,094.87$ & 1.37 & 0.47 \\
\hline 23 & hsa-miR-99b & $3,479.93$ & $2,518.45$ & -1.38 & -0.46 \\
\hline 24 & hsa-miR-29a & 844.97 & $1,133.00$ & 1.34 & 0.42 \\
\hline 25 & hsa-miR-374b & $5,524.36$ & $7,323.83$ & 1.33 & 0.41 \\
\hline 26 & hsa-miR-1280 & $4,663.46$ & $3,588.92$ & -1.30 & -0.40 \\
\hline 27 & hsa-miR-107 & $1,934.80$ & $1,482.60$ & 1.31 & -0.38 \\
\hline 28 & hsa-miR-20a & $1,288.00$ & $1,676.14$ & 1.30 & 0.38 \\
\hline 29 & hsa-miR-1275 & $1,555.18$ & $2,023.58$ & 1.30 & 0.38 \\
\hline 30 & hsa-miR-103 & $2,120.26$ & $1,665.17$ & -1.27 & -0.35 \\
\hline 31 & hsa-miR-421 & $2,081.50$ & $2,608.72$ & 1.25 & 0.33 \\
\hline 32 & hsa-let-7b & $5,514.45$ & $4,401.86$ & -1.25 & -0.32 \\
\hline 33 & hsa-let-7i & $6,675.41$ & $8,180.09$ & 1.23 & 0.31 \\
\hline 34 & hsa-miR-203 & $10,002.78$ & $11,908.19$ & 1.19 & 0.30 \\
\hline 35 & hsa-let-7e & $9,232.76$ & $7,550.89$ & -1.22 & -0.29 \\
\hline 36 & hsa-let-7c & $9,217.14$ & $7,739.46$ & -1.19 & -0.27 \\
\hline 37 & hsa-miR-15b & $9,114.19$ & $7,564.19$ & -1.20 & -0.27 \\
\hline 38 & hsa-let-7g & $5,221.45$ & $6,217.52$ & 1.19 & 0.25 \\
\hline 39 & hsa-miR-16 & $6,882.33$ & $5,591.25$ & -1.23 & -0.24 \\
\hline 40 & hsa-miR-200c & $15,029.22$ & $17,794.92$ & 1.18 & 0.23 \\
\hline 41 & hsa-miR-125a-5p & $7,915.68$ & $6,998.82$ & -1.13 & -0.18 \\
\hline 42 & hsa-miR-26a & $8,206.30$ & $9,134.90$ & 1.11 & 0.15 \\
\hline 43 & hsa-miR-25 & $8,593.85$ & $7,761.37$ & -1.11 & -0.15 \\
\hline 44 & hsa-let-7d & $13,100.11$ & $11,977.16$ & -1.09 & -0.13 \\
\hline 45 & hsa-let-7a & $18,105.40$ & $16,871.88$ & -1.07 & -0.12 \\
\hline
\end{tabular}

Sample A, MCF-7 cells; Sample B, 1386A-treated MCF-7 cells. 


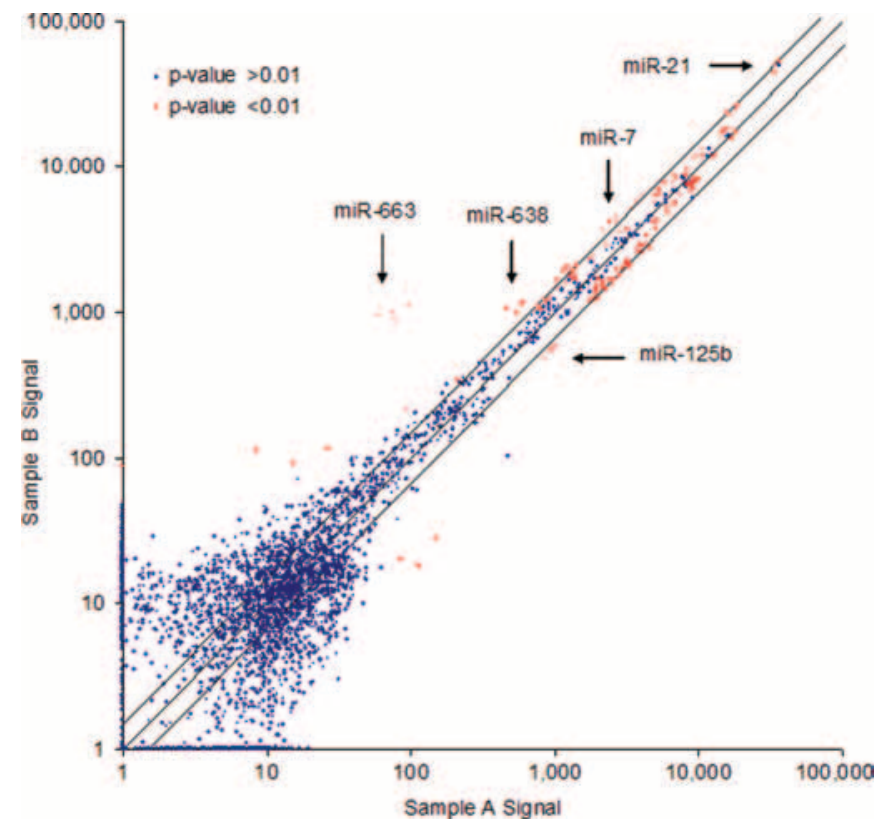

Figure 3. Comparison of the signal distribution between the control and 1386A-treated MCF-7 cells. The signal intensities of miRNAs expressed in control MCF-7 cells and 1383A-treated MCF-7 cells were compared, and their distribution according to $\mathrm{P}$-value was observed. miRNAs with $\mathrm{P}<0.01$ were labeled red, while miRNAs with $\mathrm{P}>0.01$ were labeled blue. Among the significantly altered miRNAs, miR-663, miR-21, miR-7, miR-638 and miR125 were identified particularly for their fold-change or high expression level. Sample A, MCF-7 cells; sample B, 1386A-treated MCF-7 cells.

1.5-fold difference (i.e., log2-fold change $>0.56$ ) or absolute change of least 1,000 in their expression levels between control and treated groups were considered as significant changes warranting further study. Of the up-regulated miRNAs, six showed a >1.5-fold increase: miR-663 (12.3-fold), miR-654-5p, miR-638, miR-7, miR-181b and miR-1246; four changed
>1,000: miR-21, miR-1826, miR-203 and miR-200c. Of the down-regulated miRNAs, eight showed a $>1.5$-fold decrease: miR-150 (5.7-fold), miR-125, miR-1308, miR-93, miR-182 and the miR-320 family, and several changed >1,000: miR-25 and miR-let7 family. Among them, for miR-150 and miR-654-5p, the signal intensities in both the control and treated cells were $<1,000$ (not high enough to be considered as being differentially expressed) and were excluded.

Prediction of putative target genes of differentially expressed miRNAs. In order to determine the biological function of the differentially expressed miRNAs, we further predicted the putative downstream targets of the 1386A-regulated miRNAs. It was found that the majority of miRNA genes dysregulated by $1386 \mathrm{~A}$ appeared to be associated with cancer development, progression and metastasis. Silico analysis using TargetScan (http://www.targetscan.org/) showed that several dysregulated miRNAs potentially targeted transcripts encoding known tumor-suppressor factors, such as components of BCL2, PDCD4 and PTEN, as well as several effectors and regulators of the TGF $\beta$ signaling pathway (Table II). These predicted targets can be experimentally validated with further studies if necessary. Most of the miRNAs potentially targeting the above targets were deregulated by 1386A (Table I). Altogether, these results indicate that some of the antineoplastic properties of 1386A may arise from its effects on the levels of miRNAs targeting transcripts encoding key regulators of cell homeostasis, and the putative mechanism of activation of $1386 \mathrm{~A}$ may be roughly predicted by analyzing alteration of miRNA profiles (Fig. 4).

\section{Discussion}

Cell viability assay indicated that the growth inhibition of MCF-7 by 1386A showed a time- and dose-dependent effect,

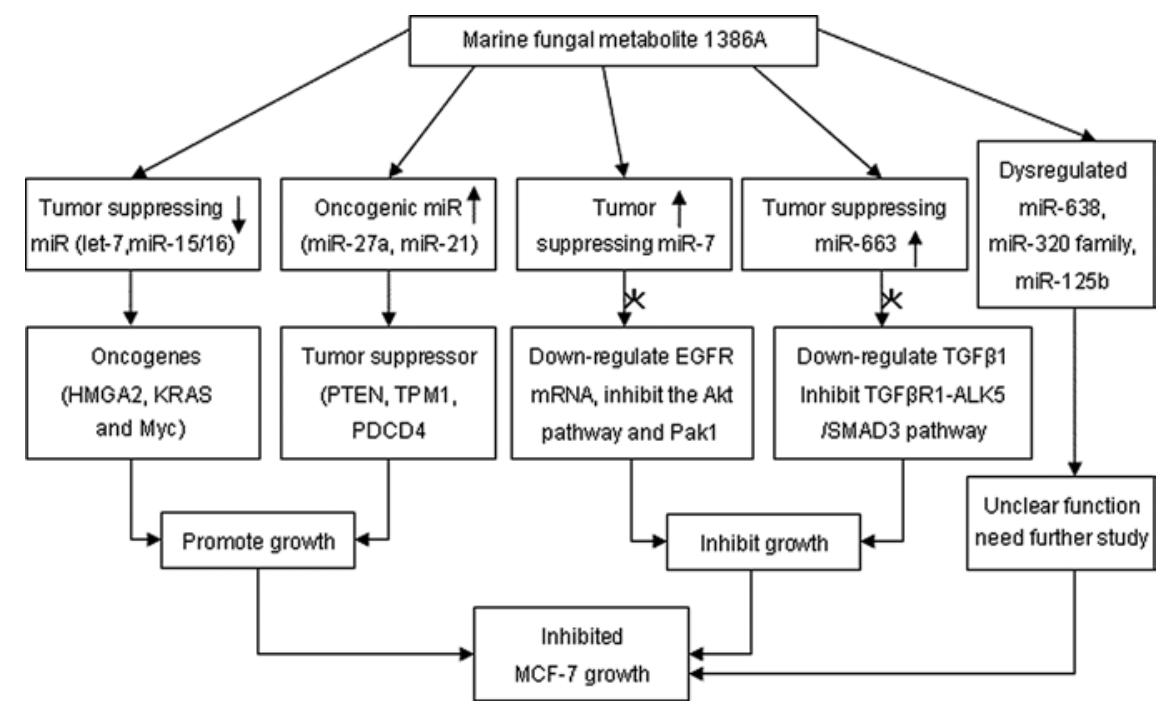

Figure 4. A proposed model showing the functional mechanism of marine fungal metabolite 1386A on MCF-7 cells through regulaton of miRNAs. miRNAs may play an intricate role in 1386A-induced cytotoxicity in breast cancer. Although tumor suppressor miRNAs (let-7a and miR-15/16) were down-regulated and oncogenic miRNAs (miR-21 and miR-27a) were up-regulated, the growth of MCF-7 cells was inhibited. Their function may be counteracted by upregulated miR-7 and miR-663, which target EGFR and TGF $\beta 1$, respectively. Dysregulated miRNAs with no previous functional implications may target important genetic alterations and assist in exerting cytotoxicity of $1386 \mathrm{~A}$ to MFC-7 cells, and thus require further study. It is worthwhile to mention that TGF $\beta 1$ was targeted by miR-663 alone, as well as miR-7 and EGFR. 


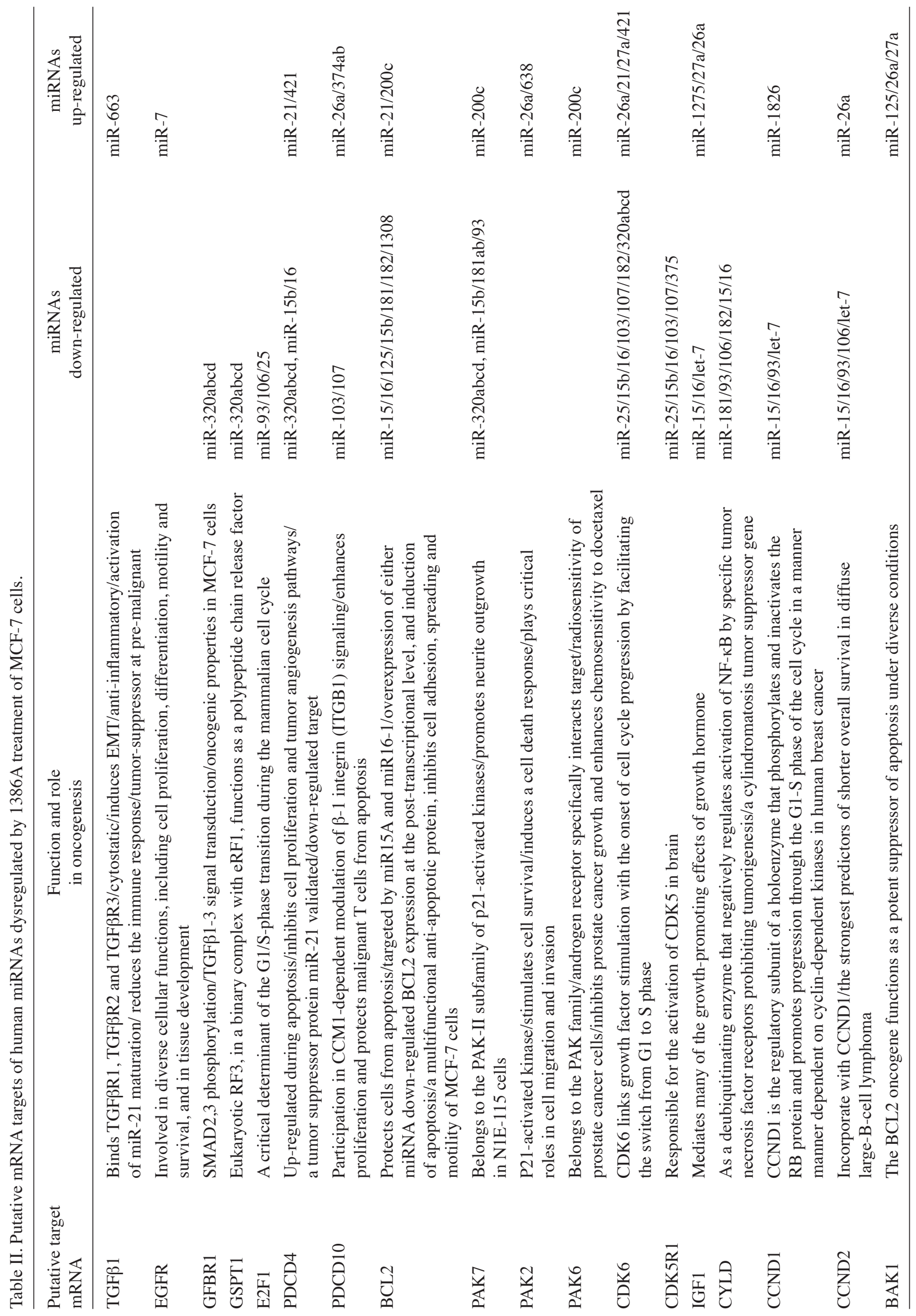


proving its promising properties as an antineoplastic agent. However, this trend was not so obvious, particularly at a low concentration $(<10 \mu \mathrm{mol} / \mathrm{l})$ (Fig. 2). The inhibition ratio unexpectedly decreased with incubation time which may be explained by the reason that, at a low concentration, 1386A did not inhibit the exponential growth phase effectively (0-48 h). Notably, after treatment with $1386 \mathrm{~A}(15 \mu \mathrm{mol} / \mathrm{l})$ for $48 \mathrm{~h}$, MCF-7 cell growth was almost suspended. This means that tumor cells after treatment with $1386 \mathrm{~A}$ at $15 \mu \mathrm{mol} / 1$ for $48 \mathrm{~h}$ reached a proliferation and death balance status. Therefore, without obvious cell death and apoptosis, alterations in miRNA expression levels may be a direct change induced by $1386 \mathrm{~A}$. $\mathrm{IC}_{50}$ value at $48 \mathrm{~h}$ was selected to investigate the effect of $1386 \mathrm{~A}$ on the global expression levels of miRNAs in MCF-7 cells.

miRNAs are an important class of gene regulators which have the potential to function as a diagnostic and prognostic tool for a variety of human cancers $(19,23,40,41)$. They constitute a novel target system for cancer treatment, because miRNA may regulate the expression of several hundred target genes, including important tumor related genes (37). Identifying miRNAs that may play a principal role in cancer therapy has become a focus of research. In terms of their critical roles in cancer progression and therapy, it is quite possible that antineoplastic agents may alter the miRNA profiles of tumor cells, as well as inhibit cell proliferation. Thus, the study of the effects of a new compound on the expression profile of miRNAs is important for the research on its unknown mechanism of activation in cancer therapy. In the present study, numerous key miRNAs were shown to be regulated by $1386 \mathrm{~A}$ treatment. Several of these miRNAs are well characterized and have been previously implicated in different cancer types (Table I). Of the $45 \mathrm{miRNAs}$ differentially expressed, most of them were linked to human cancers. A detailed analysis of the confirmed and putative gene targets of these miRNAs will shed light on the potential implications of 1386A treatment. Our study explores the possibility of global analysis of miRNAs as a new way to explore the functional mechanism of potential antimetabolites.

It has been widely reported that miRNAs play an important role in breast cancer. The expression of several miRNAs was found to be dysregulated in cancer cells when compared to normal cells. Our study identified many miRNAs that were commonly dysregulated in breast cancer. Notably, after treatment with $1386 \mathrm{~A}$ at $\mathrm{IC}_{50}, \mathrm{MCF}-7$ cells did not show a global reversal in the expression pattern of miRNAs, which was in agreement with a similar study (36), but not with another (37). We identified several tumor-suppressor miRNAs which were down-regulated following 1386A treatment, including miR-15, miR-16 and the miR-let-7 family, which potentially function by targeting oncogenes or suppressor genes involved in cell cycle and apoptosis. It was reported that miR-15/16 suppresses tumorigenicity, inhibits proliferation $(42,43)$ and causes cell cycle arrest (44), and also modulates multidrug resistance by targeting the bcl2 gene (35). Additionally, miRNA let-7a has been found to be a tumor-suppressor miRNA by targeting the oncogenes high mobility group AT-hook 2 (HMGA2), KRAS and Myc (45-47). Reduced expression of Let-7 miRNAs is associated with shortened post-operative survival $(45,48,49)$. However, the function of these down-regulated miRNAs are not in accordance with the arrested cell growth of MCF-7 cells which was noted by the MTT assay. Our study also showed the up-regulation of several important oncogenic miRNAs, such as miR-21 and miR-27a. It was reported that miR-27a is an oncogene targeting specificity protein transcription factors and the $\mathrm{G} 2 / \mathrm{M}$ checkpoint in breast cancer cells (50). miR-21 should be considered particularly noteworthy for its high expression level and significant alteration. As the most common up-regulated miRNA in solid tumors, miR-21 functions as a tumor oncogene and regulates tumorigenesis through targeting phosphatase and tensin homolog (PTEN) (51), tropomyosin-1 (TPM-1) (52) and programmed cell death protein 4 (PDCD4) (53-55). The up-regulation of these miRNAs after 1386A treatment was in contrast with the inhibition of MCF-7 cell growth (Fig. 4).

The above controversial phenomenon may be explained by the following putative reasons with relevant literature review. Firstly, it is possible that the MCF-7 cell resistant to $1386 \mathrm{~A}$ may arise from a new mechanism in order to resist this cytotoxicity. However, the possibility is very small, since the time is too short for the occurrence of drug-resistance. Secondly, most of those critical putative mRNA targets are not regulated by only one miRNA (Table I). Even when the effect of several miRNAs mentioned above has been determined, the final activation and expression of the target mRNA cannot be simply predicted, as other miRNAs which target the same mRNA may attenuate or even reverse the function of a single miRNA. Finally, there are many undetermined factors in cell signaling pathways. miRNAs have mutual effects with other genes or proteins through the signaling pathway network. Another pathway may exist which has not been found and its effect may be more powerful than miRNA-21 (Figs. 3 and 4), which may explain why the expression of miR-21 increases and the inconsistency between its function of promoting tumor growth and inhibiting the growth of MCF-7 cells after treatment with 1386A.

Fortunately, there are several mRNAs which are targeted by only one significantly altered miRNA and whose final effect may be unquestionable (Table I). Among them, miR-663, miR-7, miR-93 and miR-25 require further discussion. Taking the fold-change into consideration, special attention should be paid to miR-663 (Fig. 3, Table I). Bioinformatic predictions suggest that the human TGF $\beta 1$ mRNA 3'-untranslated region contains five miR-663 target sites. It is reported that miR-663 targets TGF $\beta 1$ transcripts (56), which are associated with invasion and metastasis of gastric cancer through the activation of the TGF $\beta$ R1-ALK5/SMAD3 pathway (57), functioning as a tumor-suppressor miRNA that induces mitotic catastrophic growth arrest in human gastric cancer cells (56). The up-regulated miR-663 as a result of treatment with 1386A may decrease the expression level of TGF $\beta 1$ and inhibit the TGF $\beta$ R1-ALK5/SMAD3 pathway. The mechanism of cytotoxicity of $1386 \mathrm{~A}$ on MCF-7 cells may be similar to that of resveratrol on SW480 cells (58). Regarding miR-7, the human EGFR mRNA 3'-untranslated region contains three miR-7 target sites. In our study, we found that only miR-7 acts on the EGFR. It has been reported that miR-7 is a potential tumor suppressor in glioblastoma targeting critical cancer pathways, which potently down-regulates EGFR mRNA and protein expression, and inhibits the Akt pathway via targeting upstream regulators inducing cell cycle arrest and cell death 
(59). Similar results have been found in other cell lines (lung and breast). Furthermore, miR-7 also attenuates activation of protein kinase B (Akt) and extracellular signal-regulated kinase $1 / 2$, coordinately regulating EGFR signaling (60). The up-regulated miR-7 after 1386A treatment may inhibit the expression of EGFR and shut down the EGFR signal pathway related to the inhibited proliferation of the MCF-7 cells. Petrocca et al found the miR-106b-miR-93-miR-25 cluster which is activated by E2F1 and up-regulated in human adenocarcinomas, alters the response of gastric cancer cells to TGF $\beta$, affecting both cell cycle arrest and apoptosis (61). What is more, miR-93 promotes tumor growth and angiogenesis by targeting the integrin- $\beta 8$ oncogene (62). Another study showed that higher expression of miR-93 was significantly correlated with a poor prognosis in serous ovarian carcinoma (63). The down-regulaion of miR-25 and miR-93 after 1386A treatment explains the inhibited proliferation of MCF-7 cells.

miR-663, miR-7, miR-93 and miR-25 have been implicated in the inhibition of cell proliferation, development and metastasis through TGF $\beta$ and EGFR signaling pathway. Up-regulation of these miRNAs and their putative function were in accordance with the inhibitory effect of $1386 \mathrm{~A}$, while the dysregulation of other miRNAs (miR-21/27a and miR-15/16/let-7) was not, reasonably arousing the predication that 1386A may inhibit the growth of MCF-7 cells through the TGF $\beta 1$ and EGFR signaling pathways. However, other studies have shown that 5-FU inhibits the growth of MCF-7 cells through miR-21-related miRNA and their signaling pathway (37). In our study, 1386A was able to exert its anticancer biological activity under the condition of up-regulating miR-21 expression (Fig. 4). Therefore, we primarily predict that the combination of 5-FU and 1386A may show stronger inhibition of MCF-7 cell growth. Although the absolute levels of miRNAs dysregulated by $1386 \mathrm{~A}$ as well as their activities on target transcripts in MCF-7 cells have not be ascertained, the above results suggested that $1386 \mathrm{~A}$ treatment may alter the levels of the transcripts encoded by those significantly altered miRNAs (Table I). Similar relationships were identified in another study (58).

The dysregulation of the global miRNA expression profiles, including important cancer-associated miRNAs after 1386A treatment, indicates an important role of miRNAs in chemotherapy and the existence of potential specific miRNA targets for 1386A. However, the mechanism of how 1386A alters miRNA expression remains poorly understood. The observation that an antineoplastic agent is able to regulate the expression of certain miRNAs, may indicate its potential DNA-synthesis-inhibiting mechanism. Theoretically, it is possible that $1386 \mathrm{~A}$ may get incorporated into the miRNA gene transcript, causing dysregulation of miRNAs and altering their primary function, while the dysregulation of miRNAs may be just an indirect alteration, for instance, caused by targeting up-stream signal pathway of miRNAs.

In summary, the newly identified compound 1386A shows promising antineoplastic potential and warrants further study for its excellent time- and dose-dependent inhibition of MCF-7 cell growth. The modification of the miRNA expression profile caused by $1386 \mathrm{~A}$ in MCF-7 cells was also identified. The pharmacodynamic mechanism could be attributed in part to its direct influence on several miRNAs (miR-663 and miR-7), of which the effect may be more powerful than other miRNAs (miR-21 and let-7 families). We are initiating further studies to verify certain predictions of the present study and confirm whether 1386A exerts its antineoplastic potential through the up-regulation of tumor-suppressor miRNAs miR-663 and miR-7 which are related to the TGF $\beta 1$ and EGFR signaling pathways.

\section{Acknowledgements}

This study was funded by Guandong Province Science and Technology Project (2008A030201009), the Sun Yat-sen University Laboratory Open Foundation Project (KF200722) and the National University Student Innovation Training Project (2007).

\section{References}

1. Furumai T, Igarashi Y, Higuchi H, Saito N and Oki T: Kosinostatin, a quinocycline antibiotic with antitumor activity from Micromonospora sp. TP-A0468. J Antibiot 55: 128-133, 2002.

2. Williams PG, Buchanan GO, Feling RH, Kauffman CA, Jensen PR and Fenical W: New cytotoxic salinosporamides from the marine Actinomycete Salinispora tropica. J Org Chem 70: 6196-6203, 2005.

3. Fenical W and Jensen PR: Developing a new resource for drug discovery: marine actinomycete bacteria. Nat Chem Biol 2: 666-673, 2006

4. Blunt JW, Copp BR, Hu WP, Munro MH, Northcote PT and Prinsep MR: Marine natural products. Nat Prod Rep 24: 31-86, 2007.

5. Ambros V: The functions of animal microRNAs. Nature 431: 350-355, 2004

6. Zhang B, Stellwag EJ and Pan X: Large-scale genome analysis reveals unique features of microRNAs. Gene 443: 100-109, 2009.

7. Ambros V: microRNAs: tiny regulators with great potential. Cell 107: 823-826, 2001.

8. Zhang B, Wang Q and Pan X: MicroRNAs and their regulatory roles in animals and plants. J Cell Physiol 210: 279-289, 2007.

9. Lewis BP, Shih IH, Jones-Rhoades MW, Bartel DP and Burge CB: Prediction of mammalian microRNA targets. Cell 115: 787-798, 2003.

10. Hatfield SD, Shcherbata HR, Fischer KA, Nakahara K, Carthew RW and Ruohola-Baker H: Stem cell division is regulated by the microRNA pathway. Nature 435: 974-978, 2005.

11. Hwang HW and Mendell JT: MicroRNAs in cell proliferation, cell death, and tumorigenesis. Br J Cancer 94: 776-780, 2006.

12. Leung AK, Calabrese JM and Sharp PA: Quantitative analysis of Argonaute protein reveals microRNA-dependent localization to stress granules. Proc Natl Acad Sci USA 103: 18125-18130, 2006.

13. Leung AK and Sharp PA: microRNAs: a safeguard against turmoil? Cell 130: 581-585, 2007.

14. Zhang B, Pan X and Anderson TA: MicroRNA: a new player in stem cells. J Cell Physiol 209: 266-269, 2006.

15. Calin GA, Sevignani C, Dumitru CD, et al: Human microRNA genes are frequently located at fragile sites and genomic regions involved in cancers. Proc Natl Acad Sci USA 101: 2999-3004, 2004.

16. Calin GA, Dumitru CD, Shimizu M, et al: Frequent deletions and down-regulation of micro-RNA genes miR15 and miR16 at 13 q14 in chronic lymphocytic leukemia. Proc Natl Acad Sci USA 99: 15524-15529, 2002.

17. Calin GA and Croce CM: MicroRNA signatures in human cancers. Nat Rev Cancer 6: 857-866, 2006.

18. Cheng AM, Byrom MW, Shelton J and Ford LP: Antisense inhibition of human miRNAs and indications for an involvement of miRNA in cell growth and apoptosis. Nucleic Acids Res 33: 1290-1297, 2005

19. Blenkiron C and Miska EA: miRNAs in cancer: approaches, aetiology, diagnostics and therapy. Hum Mol Genet 16 Spec No 1: R106-R113, 2007.

20. Iorio MV, Ferracin M, Liu CG, et al: MicroRNA gene expression deregulation in human breast cancer. Cancer Res 65: 7065-7070, 2005.

21. Lu J, Getz G, Miska EA, et al: MicroRNA expression profiles classify human cancers. Nature 435: 834-838, 2005. 
22. Zhang B, Pan X, Cobb GP and Anderson TA: microRNAs as oncogenes and tumor suppressors. Dev Biol 302: 1-12, 2007.

23. Zhang B and Farwell MA: microRNAs: a new emerging class of players for disease diagnostics and gene therapy. J Cell Mol Med 12: 3-21, 2008

24. Ma L, Teruya-Feldstein J and Weinberg RA: Tumour invasion and metastasis initiated by microRNA-10b in breast cancer. Nature 449: 682-688, 2007.

25. Huang Q, Gumireddy K, Schrier M, et al: The microRNAs miR-373 and miR-520c promote tumour invasion and metastasis. Nat Cell Biol 10: 202-210, 2008.

26. Tavazoie SF, Alarcon C, Oskarsson T, et al: Endogenous human microRNAs that suppress breast cancer metastasis. Nature 451: $147-152,2008$

27. Meng F, Henson R, Lang M, et al: Involvement of human micro-RNA in growth and response to chemotherapy in human cholangiocarcinoma cell lines. Gastroenterology 130: 2113-2129, 2006.

28. Blower PE, Verducci JS, Lin S, et al: MicroRNA expression profiles for the NCI-60 cancer cell panel. Mol Cancer Ther 6 : $1483-1491,2007$

29. Blower PE, Chung JH, Verducci JS, et al: MicroRNAs modulate the chemosensitivity of tumor cells. Mol Cancer Ther 7: 1-9, 2008

30. Si ML, Zhu S, Wu H, Lu Z, Wu F and Mo YY: miR-21-mediated tumor growth. Oncogene 26: 2799-2803, 2007.

31. Li Y, Zhu X, Gu J, et al: Anti-miR-21 oligonucleotide enhances chemosensitivity of leukemic HL60 cells to arabinosylcytosine by inducing apoptosis. Hematology 15: 215-221, 2010.

32. Kovalchuk O, Filkowski J, Meservy J, et al: Involvement of microRNA-451 in resistance of the MCF-7 breast cancer cells to chemotherapeutic drug doxorubicin. Mol Cancer Ther 7 : 2152-2159, 2008

33. Miller TE, Ghoshal K, Ramaswamy B, et al: MicroRNA-221/222 confers tamoxifen resistance in breast cancer by targeting p27Kip1. J Biol Chem 283: 29897-29903, 2008.

34. Zhao JJ, Lin J, Yang H, et al: MicroRNA-221/222 negatively regulates estrogen receptor alpha and is associated with tamoxifen resistance in breast cancer. J Biol Chem 283: 31079-31086, 2008

35. Xia L, Zhang D, Du R, et al: miR-15b and miR-16 modulate multidrug resistance by targeting BCL2 in human gastric cancer cells. Int J Cancer 123: 372-379, 2008.

36. Rossi L, Bonmassar E and Faraoni I: Modification of miR gene expression pattern in human colon cancer cells following exposure to 5-fluorouracil in vitro. Pharmacol Res 56: 248-253, 2007.

37. Shah MY, Pan X, Fix LN, Farwell MA and Zhang B 5-Fluorouracil drug alters the microRNA expression profiles in MCF-7 breast cancer cells. J Cell Physiol: Nov, 2010 (E-pub ahead of print).

38. Gao X, Gulari E and Zhou X: In situ synthesis of oligonucleotide microarrays. Biopolymers 73: 579-596, 2004.

39. Bolstad BM, Irizarry RA, Astrand M and Speed TP: A comparison of normalization methods for high density oligonucleotide array data based on variance and bias. Bioinformatics 19 185-193, 2003

40. Tricoli JV and Jacobson JW: MicroRNA: potential for cancer detection, diagnosis, and prognosis. Cancer Res 67: 4553-4555, 2007.

41. Lowery AJ, Miller N, McNeill RE and Kerin MJ: MicroRNAs as prognostic indicators and therapeutic targets: potential effect on breast cancer management. Clin Cancer Res 14: 360-365, 2008.

42. Cimmino A, Calin GA, Fabbri M, et al: miR-15 and miR-16 induce apoptosis by targeting BCL2. Proc Natl Acad Sci USA 102: 13944-13949, 2005.

43. Aqeilan RI, Calin GA and Croce CM: miR-15a and miR-16-1 in cancer: discovery, function and future perspectives. Cell Death Differ 17: 215-220, 2010

44. Xia H, Qi Y, Ng SS, et al: MicroRNA-15b regulates cell cycle progression by targeting cyclins in glioma cells. Biochem Biophys Res Commun 380: 205-210, 2009.
45. Johnson SM, Grosshans $\mathrm{H}$, Shingara J, et al: RAS is regulated by the let-7 microRNA family. Cell 120: 635-647, 2005.

46. Lee YS and Dutta A: The tumor suppressor microRNA let-7 represses the HMGA2 oncogene. Genes Dev 21: 1025-1030, 2007.

47. Sampson VB, Rong NH, Han J, et al: MicroRNA let-7a downregulates MYC and reverts MYC-induced growth in Burkitt lymphoma cells. Cancer Res 67: 9762-9770, 2007.

48. Takamizawa J, Konishi H, Yanagisawa K, et al: Reduced expression of the let-7 microRNAs in human lung cancers in association with shortened postoperative survival. Cancer Res 64: 3753-3756, 2004.

49. Akao Y, Nakagawa $Y$ and Naoe T: let-7 microRNA functions as a potential growth suppressor in human colon cancer cells. Biol Pharm Bull 29: 903-906, 2006.

50. Mertens-Talcott SU, Chintharlapalli S, Li X and Safe S: The oncogenic microRNA-27a targets genes that regulate specificity protein transcription factors and the G2-M checkpoint in MDA-MB-231 breast cancer cells. Cancer Res 67: 11001-11011, 2007.

51. Meng F, Henson R, Wehbe-Janek H, Ghoshal K, Jacob ST and Patel T: MicroRNA-21 regulates expression of the PTEN tumor suppressor gene in human hepatocellular cancer. Gastroenterology 133: 647-658, 2007.

52. Zhu S, Si ML, Wu H and Mo YY: MicroRNA-21 targets the tumor suppressor gene tropomyosin 1 (TPM1). J Biol Chem 282: 14328-14336, 2007

53. Asangani IA, Rasheed SA, Nikolova DA, et al: MicroRNA-2 (miR-21) post-transcriptionally downregulates tumor suppressor Pdcd4 and stimulates invasion, intravasation and metastasis in colorectal cancer. Oncogene 27: 2128-2136, 2008.

54. Frankel LB, Christoffersen NR, Jacobsen A, Lindow M, Krogh A and Lund AH: Programmed cell death 4 (PDCD4) is an important functional target of the microRNA miR-21 in breast cancer cells. J Biol Chem 283: 1026-1033, 2008.

55. Lu Z, Liu M, Stribinskis V, et al: MicroRNA-21 promotes cell transformation by targeting the programmed cell death 4 gene. Oncogene 27: 4373-4379, 2008.

56. Pan J, Hu H, Zhou Z, et al: Tumor-suppressive mir-663 gene induces mitotic catastrophe growth arrest in human gastric cancer cells. Oncol Rep 24: 105-112, 2010.

57. Yoo YA, Kang MH, Kim JS and Oh SC: Sonic hedgehog signaling promotes motility and invasiveness of gastric cancer cells through TGF-beta-mediated activation of the ALK5-Smad 3 pathway. Carcinogenesis 29: 480-490, 2008.

58. Tili E, Michaille JJ, Alder H, et al: Resveratrol modulates the levels of microRNAs targeting genes encoding tumor-suppressors and effectors of TGFbeta signaling pathway in SW480 cells. Biochem Pharmacol 80: 2057-2065, 2010.

59. Kefas B, Godlewski J, Comeau L, et al: microRNA-7 inhibits the epidermal growth factor receptor and the Akt pathway and is down-regulated in glioblastoma. Cancer Res 68: 3566-3572, 2008.

60. Webster RJ, Giles KM, Price KJ, Zhang PM, Mattick JS and Leedman PJ: Regulation of epidermal growth factor receptor signaling in human cancer cells by microR NA-7. J Biol Chem 284: 5731-5741, 2009.

61. Petrocca F, Visone R, Onelli MR, et al: E2F1-regulated microRNAs impair TGFbeta-dependent cell-cycle arrest and apoptosis in gastric cancer. Cancer Cell 13: 272-286, 2008.

62. Fang L, Deng Z, Shatseva T, et al: MicroRNA miR-93 promotes tumor growth and angiogenesis by targeting integrin-beta8. Oncogene 30: 806-821, 2011

63. Nam EJ, Yoon H, Kim SW, et al: MicroRNA expression profiles in serous ovarian carcinoma. Clin Cancer Res 14: 2690-2695, 2008. 